\title{
Evaluation of Turbidimetric and Nephelometric Techniques for Analytical Determination of $N$-Acetylcysteine and Thiamine in Pharmaceutical Formulations Employing a Lab-Made Portable Microcontrolled Turbidimeter and Nephelometer
}

\author{
Vagner B. dos Santos, ${ }^{a}$ Thiago B. Guerreiro, ${ }^{a}$ Willian T. Suarez, ${ }^{b}$ Ronaldo C. Faria ${ }^{a}$ and \\ Orlando Fatibello-Filho*, \\ a'Departamento de Química, Universidade Federal de São Carlos, Centro de Ciências Exatas e de Tecnologia, \\ CP 676, 13560-970 São Carlos-SP, Brazil \\ ${ }^{\mathrm{b}}$ Departamento de Química, Universidade Federal de Viçosa, Centro de Ciências Exatas e Tecnológicas, \\ 36570-000 Viçosa-MG, Brazil
}

\begin{abstract}
A análise turbidimétrica e nefelométrica sequencial (STN) para duas aplicações analíticas empregando um nefelômetro e turbidímetro microcontrolado portátil (PMTN) é proposta. O PMTN é constituído de diodos emissores de luz, fotodiodos, microcontrolador como unidade de processamento central (CPU) e um um LCD (liquid crystal display) como amostrador. Os métodos STN foram aplicados para a determinação de $N$-acetilcisteína em formulações farmacêuticas nos intervalos de concentração de $8,0 \times 10^{-5}$ a $5,0 \times 10^{-3} \mathrm{~mol} \mathrm{~L}^{-1}$ (nefelometria) e de $5,0 \times 10^{-5}$ a 1,2 $\times 10^{-3} \mathrm{~mol} \mathrm{~L}^{-1}$ (turbidimetria) com limites de detecção (LOD) de $2.6 \times 10^{-6} \mathrm{e} 7,5 \times 10^{-6} \mathrm{~mol} \mathrm{~L}^{-1}$, respectivamente. As análises STN também foram executadas para a determinação de tiamina na faixa de concentração de $5,0 \times 10^{-6}$ a $2,5 \times 10^{-4} \mathrm{~mol} \mathrm{~L}^{-1}$ e de $5,0 \times 10^{-6}$ a $1,0 \times 10^{-4} \mathrm{~mol} \mathrm{~L}^{-1} \mathrm{com}$ LOD de $5,91 \times 10^{-8}$ e $3,11 \times 10^{-8} \mathrm{~mol} \mathrm{~L}^{-1}$ respectivamente no modo nefelométrico e turbidimétrico.
\end{abstract}

Sequential turbidimetric and nephelometric (STN) analysis for two distinct analytical applications employing a portable microcontrolled turbidimeter and nephelometer (PMTN) is proposed. The PMTN is based on light emitting diodes, photodiodes and, a microcontroller as a central processing unit with a LCD (liquid crystal display) as displayer. The STN methods were applied to determine $\mathrm{N}$-acetylcysteine and two analytical curves in the concentration ranges from 8.0 $\times 10^{-5}$ to $5.0 \times 10^{-3} \mathrm{~mol} \mathrm{~L}^{-1}$ and from $5.0 \times 10^{-5}$ to $1.2 \times 10^{-3} \mathrm{~mol} \mathrm{~L}^{-1}$ were obtained to nephelometry and turbidimetry, respectively. Limits of detection (LOD) of $2.6 \times 10^{-6}$ and $7.5 \times 10^{-6} \mathrm{~mol} \mathrm{~L}^{-1}$ were acquired for these procedures. The STN analyses were also performed to determinate thiamine and two analytical curves in the concentration ranges from $5.0 \times 10^{-6}$ to $2.5 \times 10^{-4} \mathrm{~mol} \mathrm{~L}^{-1}$ and from $5.0 \times 10^{-6}$ to $1.0 \times 10^{-4} \mathrm{~mol} \mathrm{~L}^{-1}$ with LOD of $5.91 \times 10^{-8}$ and $3.11 \times 10^{-8} \mathrm{~mol} \mathrm{~L}^{-1}$ were acquired for nephelometry and turbidimetry, respectively.

Keywords: turbidimetry, nephelometry, $N$-acetylcysteine, thiamine, microcontrolled photometric detector

\section{Introduction}

Nephelometry is a spectroscopic technique based on the radiation scattered by suspended particles in a solution and sensing the radiation scattered at an angle of $90^{\circ}$ from the incident radiation beam. On the other hand, turbidimetry is a technique based on the attenuation of the incident radiation (transmitted radiation) due to particulates in suspension with a detector located at $180^{\circ}$ from the incident

*e-mail: bello@ufscar.br beam. ${ }^{1,2}$ In both techniques, the wavelength of the incident beam does not change, which characterizes an elastic scattering of incident electromagnetic radiation. The elastic scattering of electromagnetic radiation by small particles depends on the particle size $(d)$ and incident radiation beam wavelength $(\lambda)$. In general, Mie scattering or Fraunhofer diffraction is dominant for particles measuring about $1 \mu \mathrm{m}$ or larger. On the other hand, Rayleigh scattering is common for small particles $(d<<\lambda) .{ }^{3,4}$ Radiations can be scattered in different directions, but the scattering at $30 \pm 15^{\circ}, 90^{\circ}$, $180^{\circ}$ and, forward scattering (where the detector is localized 


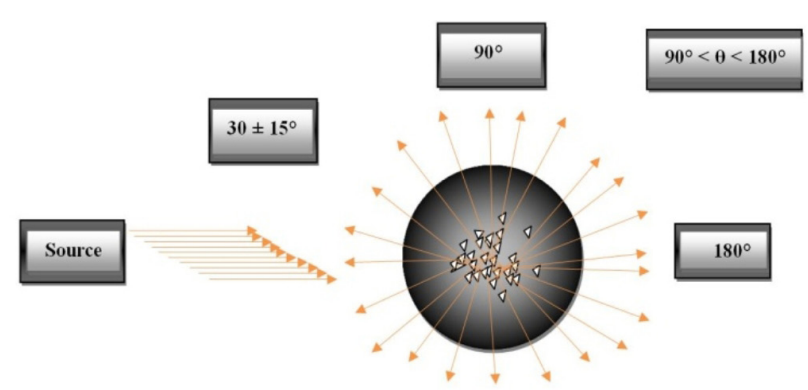

Figure 1. Scheme of the light scattering in different directions. Some arrangements between the source of the electromagnetic radiation and the detector are shown.

between $90^{\circ}$ and $180^{\circ}$ ) are widely employed for analytical purposes. The radiation scattering patterns by hypothetic particles are shown in Figure 1.

In turbidimetry, the analytical signal is not directly proportional to the intensity of the incident radiation $\left(I_{0}\right)$, but the logarithm, as can be seen in equation 1 :

turbidity $=-\log \left(\frac{I}{I_{0}}\right)$

where $I$ is the transmitted radiation. Because $I$ and $I_{0}$ change proportionately, an increase in $I_{0}$ will not increase the obtained signal. On the other hand, for nephelometric analysis, the relationship between $I, I_{0}$, and concentration $(C)$ is linear, given by equation 2 :

$I=K I_{0} C$

where $K$ is a constant for the particular instrument at controlled experimental conditions. Therefore, a more intense incident radiation produces a greater magnitude of scattered radiation that will reach the detector located at $90^{\circ}$ from the incident radiation beam. ${ }^{3}$ However, the performance of the analytical method is not only dependent on the power of the incident radiation beam and sensitivity of the sensor but also dependent on the characteristics of the suspension to be analyzed. This is due to distinct radiation scattering patterns that can be generated by particles in suspension. ${ }^{5}$ Some properties of the suspension such as particle shape and size are affected by changes in $\mathrm{pH}$ value, concentration of the reagents, and surfactants that are used to prepare the suspensions. Other variables such as rate and order of mixing, time for stabilization of the suspension and temperature of the solution are other factors that affect the properties of the particles, and consequently, the analytical signal. Thus, this variables should be carefully controlled in order to obtain a good analytical performance. ${ }^{6}$

Turbidimeters or nephelometers are widely used to measure the radiation scattering. Those are categorized according to the type of radiation source used (LASER, incandescent light (tungsten filament lamp) and light emitting diode (LED)), angle between the detector and the radiation source $\left(30^{\circ}, 90^{\circ}, 180^{\circ}\right.$, and $\left.90^{\circ}<\theta<180^{\circ}\right)$ and the presence of multiples detectors (multibeams). Optical instruments based on LED as a radiation source have been described in the literature; ${ }^{7-16}$ however, a few were dedicated to the construction of either turbidimeters or nephelometers. ${ }^{12}$ Besides, with the use of microcontrollers, the analytical instrumentation becomes portable and presents a lower cost, lower power consumption and higher stability. On the other hand, few microcontrollers have been applied as central processing units (CPU) mainly to lab-made instrumentation. ${ }^{13,14}$ Santos et al. ${ }^{17}$ in a previous work developed a microcotrolled nephelometer applied to determine potassium ions in beverages with good performance. A LOD of $4.0 \times 10^{-7} \mathrm{~mol} \mathrm{~L}^{-1}$ to potassium determination was obtained. Additionally, microcontrolled equipment can be very useful for providing favorable features of both (turbidimetry and nephelometry techniques) due to the possibility of the multi-detector arrangements (multichannel detection). In fact, a multichannel microcontrolled device can increase the linear calibration range because turbidimetric analyses are often used to determine analytes in concentrated media, while nephelometric analyses are used for less concentrated solutions. Besides, particle size can change the intensity and direction of the radiation scattering and so, a method can be more sensitive than another. Different limits of detection can be obtained in function of this property. ${ }^{6}$ In order to explore those features, a microcontrolled turbidimeter and nephelometer to perform multiple sequential tasks during a short time is described. This equipment was applied for sequential determination of $\mathrm{N}$-acetylcysteine and thiamine in pharmaceutical formulations in order to verify its performance and applicability.

$N$-Acetylcysteine (L- $\alpha$-acetamido- $\beta$-mercaptopropionic acid) is a drug mainly used due to its thiol group (R-SH) that gives its reducing properties. This drug is used mainly as a mucolytic and antioxidant agent. ${ }^{18,19}$ HPLC (high performance liquid chromatography) with amperometric, ${ }^{20}$ fluorimetric, ${ }^{21}$ mass $^{22}$ and ultraviolet ${ }^{23}$ detectors have been widely applied as the main methods of detection.

Thiamine (vitamin B1) is very important to prevent a disease known as Beriberi, whose frequent symptoms are insomnia, nervousness, irritability, depression, loss of appetite, abdomen and chest pain, and problems associated with lack of memory and concentration. ${ }^{24,25}$ The American Pharmacopoeia ${ }^{26}$ recommended the spectrofluorimetric method based on thiochrome formation in which fluorescence is measured between 400 and $450 \mathrm{~nm}$. The British Pharmacopoeia ${ }^{27}$ recommends a gravimetric procedure by the reaction of thiamine with silicotungstic 
acid. Polarographic, ${ }^{28}$ potentiometric, ${ }^{29}$ chromatographic, ${ }^{30}$ electrophoretic, ${ }^{31}$ fluorescence ${ }^{32}$ and spectrophotometric ${ }^{33}$ methods have also been employed.

\section{Experimental}

\section{Reagents and solutions}

Deionized water (resistivity $>18.2 \mathrm{M} \Omega \mathrm{cm}$ ) was obtained from a Milli-Q plus system (Millipore Corp., Bedford, MA, USA) and used to prepare all aqueous solutions. A $8.5 \times 10^{-3}$ mol L-1 $N$-acetylcysteine (Sigma) stock solution and a $0.1 \mathrm{~mol} \mathrm{~L}^{-1}$ copper sulfate (Mallinckrodt) stock solution were prepared daily. A $1.5 \%(\mathrm{~m} / \mathrm{v})$ polyethylene glycol (Aldrich) solution and concentrated hydrochloric acid (Merck) were also used. Tablet samples of $N$-acetylcysteine (10 of each sample) purchased from local pharmacies were macerated and masses of 2.0 and $6.0 \mathrm{~g}$ were weighed and dissolved in deionized water to prepare $100 \mathrm{~mL}$ of $\mathrm{N}$-acetylcysteine solution. The solutions containing the active principle were subjected to ultrasound for $30 \mathrm{~min}$ and then filtered through $0.5 \mu \mathrm{m}$ filter paper. A $7.5 \times 10^{-3} \mathrm{~mol} \mathrm{~L}^{-1}$ thiamine (Sigma) stock solution and $7.5 \times 10^{-3} \mathrm{~mol} \mathrm{~L}^{-1}$ silicotungstic acid (Sigma) were prepared daily. The tablets of thiamine (10 of each sample) also purchased from local pharmacies were macerated and masses of $300 \mathrm{mg}$ were weighed and dissolved in deionized water to prepare $500 \mathrm{~mL}$ of stock solutions. After, stock solutions were subjected to ultrasound for $30 \mathrm{~min}$ and then filtered.

\section{Apparatus}

All electrochemical measurements were performed using a potentiostat/galvanostat (Autolab, Eco Chemie, Netherlands) controlled by the GPES 4.9 software (Eco Chemie). These measurements were done using a conventional three electrode electrochemical cell $(30 \mathrm{~mL})$. A hanging mercury drop electrode (HMDE), Metrohm (model EA 410), was used as the working electrode, $\mathrm{Ag} / \mathrm{AgCl}$ (3.0 mol L-1 $\mathrm{KCl}$ ), Metrohm (model AG 9101), as the reference electrode and platinum foil as the counter electrode. An Orion model EA 940 (USA) pH meter equipped with a combined glass electrode (Analion, model V 620), with an external $\mathrm{Ag} / \mathrm{AgCl}\left(3.0 \mathrm{~mol} \mathrm{~L}^{-1} \mathrm{KCl}\right)$ reference electrode, was used to determine $\mathrm{pH}$. A Micronal model B330 (USA) conductivimeter with a glass conductivity cell was also used. An Ocean Optics model USB 2000 (USA) spectrophotometer equipped with an optical fiber (model ps50-2) was used to measure the emission spectra of LED, which was used as radiation sources. The ultrabright blue LED (InGaN, $465 \mathrm{~nm}$ ) model OVLGB0C6B9 was acquired from Electronics (USA), and the infrared LED (AlGaAs, $880 \mathrm{~nm}$ ) model QED 223 from Fairchild Semiconductor (China). Photodiodes (Texas Advanced Optoelectronic Solutions, USA), model TSLB257 (visible sensor), and TSL260R-LF (IR sensor) were used as the detectors. ${ }^{34,35}$ A peripheral interface controller (PIC) microcontroller, acquired from Microchip Technology (USA), model PIC18F4550, ${ }^{36}$ was used as the CPU. Dynamic light scattering (DLS) measurements were performed employing a Zetasizer from Malvern Instruments model Nano ZS using a standard LASER of He-Ne with maxima emission at $632.8 \mathrm{~nm}$ and maximum power of $4 \mathrm{~mW}$.

\section{Portable microcontrolled turbidimeter and nephelometer}

The wavelengths of maximum emission $\left(\lambda_{\max }\right)$ for blue and infrared LED were 465 and $880 \mathrm{~nm}$, respectively. The blue LED was chosen because most turbidity analyses found in the literature use radiation sources that emit light ranging from 400 to $480 \mathrm{~nm}$ in the electromagnetic spectrum. ${ }^{3,6}$ However, the infrared LED (IR LEDs) was installed in the portable microcontrolled turbidimeter and nephelometer (PMTN) in order to determine particles in colored suspension. This strategy was necessary because the presence of these colored suspension led to a decrease of the light scattering by absorption of incident beam leading to systematic errors. As already known, the radiation source of a nephelometer should be more intense than that of a turbidimeter. ${ }^{3,6,17}$ Thus, the ultrabright LED was coupled to a BC548 transistor driven by the microcontroller to provide 50 and $100 \mathrm{~mA}$ of current to the blue and IR LEDs, respectively, supplying high-intensity radiation for the nephelometric analyses. ${ }^{17}$ On the other hand, whether the same LED was displaced to $180^{\circ}$ of the sensor as in turbidimetric analyses, the sensor will lead to an unwanted saturation. For this, a low electric current is needed to provide a low luminous intensity to the turbidimetric module. A working current lower than $1 \mathrm{~mA}$ in LED causes instability in the luminescence of the radiation source. So, $2.0 \mathrm{~mA}$ was selected to supply a steady radiation source to the PMTN which showed good reproducibility, precision and accuracy. The electric currents were limited by the variable resistor of 5 and $1 \mathrm{k} \Omega$ to supply the electric current mentioned above. The details of the use of TSLB257 (blue sensor), TSL260R-LF (infrared sensor) photodiodes and $18 \mathrm{~F} 4550^{36}$ microcontroller as a CPU for the PMTN were described by Santos et al. ${ }^{17}$ in previous article of our research group. Figure 2 illustrates how the LED, photodiodes and LCD were coupled to the PIC microcontroller.

A $12 \mathrm{~V}$ rechargeable battery $\left(7.0 \mathrm{~A} \mathrm{~h}^{-1}\right)$ was used to provide the power to the PMTN for a period of $35 \mathrm{~h}$ without interruption. The analyses were performed in batch, although it may be adapted for flow injection analyses. The 


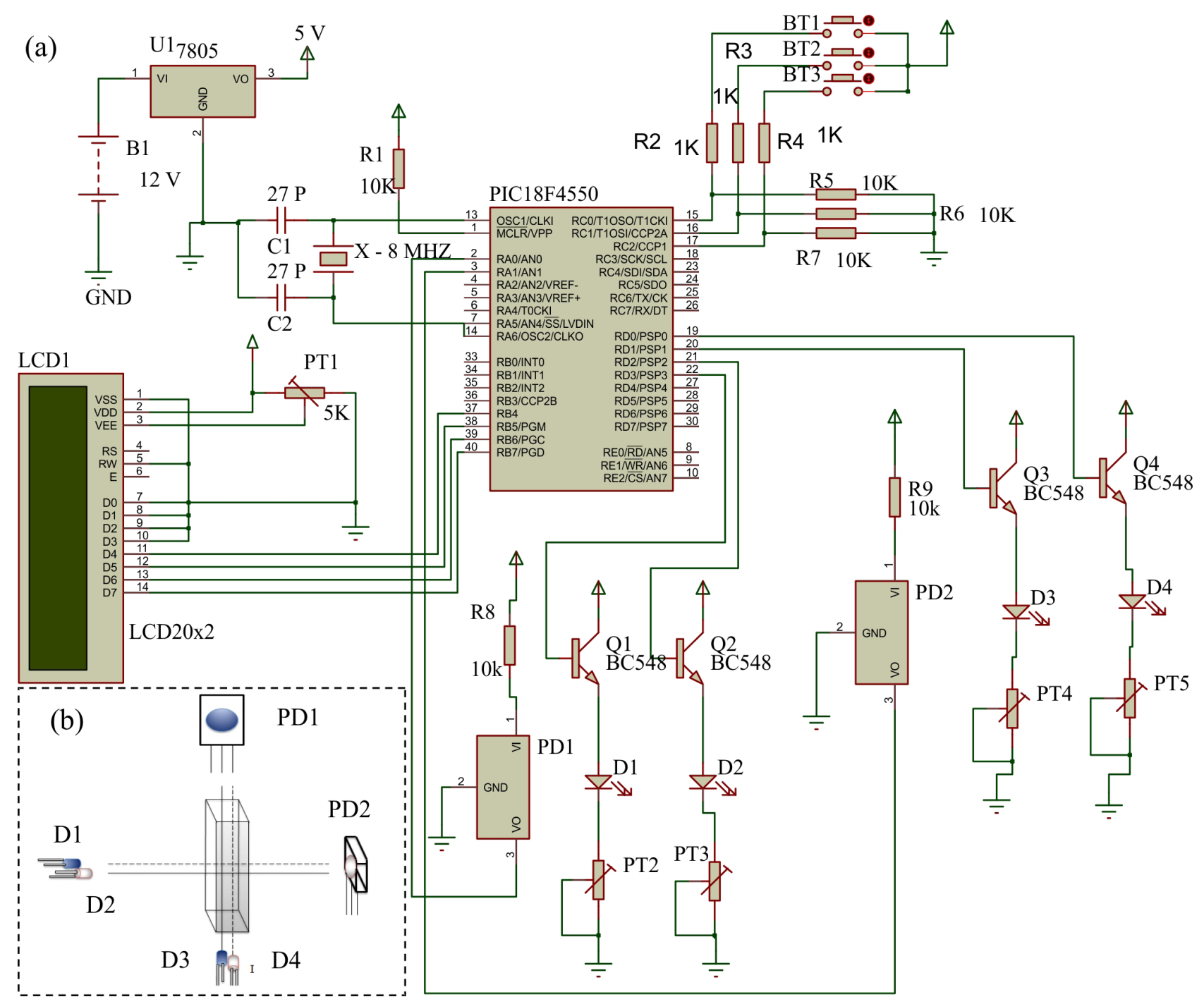

Figure 2. Electronic circuit of the developed PMTN (a). The arrangement of cuvette, LED (D1, D2, D3 and D4), and photodiodes (PD1 and PD2) are also shown (b). Power supply (battery of +12 V); GND is ground; PT1, PT2, PT3, PT4 e PT5 are 5, 1, 5, 5 and $1 \mathrm{k} \Omega$ respectively; the blue LED1 (LED used to nephelometry; dashed line) and LED3 (LED used to turbidimetry; solid line) and the blue PD1 (photodiode 1) are employed to STN analyses with measurement at $465 \mathrm{~nm}$. Similarly, the infrared LED2 (LED used to turbidimetry) and LED4 (LED used to nephelometry) and PD2 (photodiode 2) are employed to STN analyses with measurement at $880 \mathrm{~nm}$. BT1, BT2 and BT3 are the buttons (switches) respectively.

measures of instrument noise, reading of the blank, and then the turbidimetric and nephelometric sequential analyses at $465 \mathrm{~nm}$ or at $880 \mathrm{~nm}$, respectively, are executed by applying a program written in language $\mathrm{C}$ embedded within PIC memory. Additional details of this program were presented in our previous work. ${ }^{17}$ However, in order to perform the STN analyses new routines of software were developed to select the proper LED and photodiode. The PMTN takes only $0.50 \mathrm{~s}$ to execute the STN analyses and display the data on the LCD screen.

\section{Evaluation of performance of the PMTN}

To verify the performance and reliability of the proposed microcontrolled turbidimeter and nephelometer
(PMTN), studies of stability, signal-to-noise ratio and calibration were performed. These assays were carried out on different days.

\section{Analytical application employing the PMTN}

Analytical application of the PMTN was evaluated in the STN determination of $N$-acetylcysteine and thiamine in pharmaceutical formulations. In order to optimize the applied analytical methods, the variables related to the formation of a suspension, such as the concentration of the reagent, analyte, surfactant and the $\mathrm{pH}$ solution, were evaluated employing a factorial design for each studied analyte. To determine $N$-acetylcysteine, the method based on the precipitation reaction with copper ions $\left(\mathrm{Cu}^{2+}\right)$ was used, 


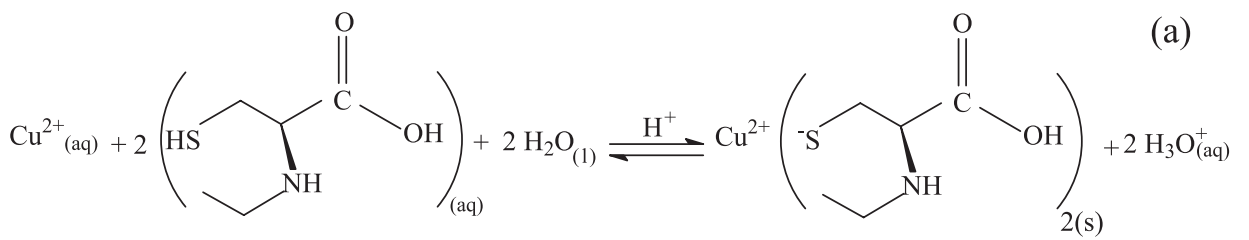

$$
2\left[\mathrm{C}_{12} \mathrm{H}_{17} \mathrm{~N}_{4} \mathrm{OS}\right]_{(\mathrm{aq})}^{2+}+\left[\mathrm{Si}\left(\mathrm{W}_{3} \mathrm{O}_{10}\right)_{4}\right]_{(\mathrm{aq})}^{4-} \stackrel{\mathrm{H}^{+}}{\rightleftharpoons}\left[\mathrm{C}_{12} \mathrm{H}_{17} \mathrm{~N}_{4} \mathrm{OS}\right]_{2}\left[\mathrm{Si}\left(\mathrm{W}_{3} \mathrm{O}_{10}\right)_{4}\right]_{(\mathrm{s})}
$$

Figure 3. Chemical reaction between $N$-acetylcysteine and $\mathrm{Cu}^{2+}$ ions (a) and thiamine with silicotungstate ions (b).

Figure 3(a). This method was adapted from a conductimetric method developed by the Janegitz et al. ${ }^{37}$ for turbidimetric and nephelometric analyses. For the determination of thiamine (vitamin B1), silicotungstic acid was used as the precipitation agent, ${ }^{38}$ Figure 3(b). However, in both reactions, polyethylene glycol was used as a surfactant and the $\mathrm{pH}$ of the solution was strongly acidified and adjusted with hydrochloric acid. Each analyte was analyzed separately by the turbidimetric and nephelometric techniques applied sequentially with an analysis time of 0.50 s. In Figure 3, both reactions are shown. In Table 1, the levels of the variables studied in each of the applied methods are shown.

According to the literature, the order in which the solutions are added to prepare the suspension can lead to a variation of $3.0 \%$ in the analytical response, ${ }^{39}$ thus the following procedure was performed and maintained: the reagent was prepared at a specific $\mathrm{pH}$ and added into a $5.0 \mathrm{~mL}$ volumetric flask and the analyte was then added followed by the addition of surfactant. During the method for the $N$-acetylcysteine determination, 3 min were necessary to allow the formation and stabilization of the suspension in order to acquire accurate and precise data. On the order hand, this procedure was not necessary to determine thiamine because of the fast reaction time and good stabilization of the suspension. This procedure was performed for all experiments. To minimize changes in the properties of the precipitate such as shape and size of the particles, all experiments were carried out at a controlled temperature of $20 \pm 2{ }^{\circ} \mathrm{C} .{ }^{39,40}$ Moreover, because the PMTN is able to perform the turbidimetric and nephelometric measurements in only $0.25 \mathrm{~s}$ per analysis, the formed suspension has the same features during both the measurement procedures. For STN analyses, a time of $0.50 \mathrm{~s}$ was required.

\section{Study of particle size}

In order to certify the influence of particle size on light scattering, mainly on the limit of detection for STN analyses, assays of size particles were carried out by DLS measurements. For this purpose, the same optimized turbidimetric and nephelometric methods were carried out with solutions of $5.0 \times 10^{-3} \mathrm{~mol} \mathrm{~L}^{-1} N$-acetylcysteine and $5.0 \times 10^{-5} \mathrm{~mol} \mathrm{~L}^{-1}$ thiamine. Operational parameter of the DLS technique, such as particle size limit, density, and refractive index of the suspensions was necessary.

\section{Results and Discussion}

\section{Stability evaluation of the PMTN}

Tests of stability for a series of measurements during a period of $6 \mathrm{~h}$ on three different days were executed, and the graph of stability is presented as Supplementary Information, Figure S1. The equipment was stable, independent of the time and day in which it was used. In fact, a very small variation of the signal was observed between the nephelometric measurements, generating a RSD (relative standard deviation) of $0.05 \%$. For this

Table 1. Variables of the $2^{4}$ factorial design applied to determine $N$-acetylcysteine and thiamine

\begin{tabular}{|c|c|c|c|c|c|c|c|c|c|}
\hline \multicolumn{5}{|c|}{$\mathrm{N}$-acetylcysteine } & \multicolumn{5}{|c|}{ Thiamine } \\
\hline Level & $\begin{array}{l}\text { N-act. }{ }^{\mathrm{a}} / \\
\left(\mathrm{mol} \mathrm{L}^{-1}\right) \\
\end{array}$ & $\begin{array}{c}\mathrm{Cu}^{2+} / \\
\left(\mathrm{mol} \mathrm{L}^{-1}\right)\end{array}$ & $\begin{array}{c}\mathrm{PEG}^{\mathrm{b}} / \\
(\mathrm{m} / \mathrm{v}) \%\end{array}$ & $\begin{array}{c}\mathrm{HCl} / \\
\left(\mathrm{mol} \mathrm{L}^{-1}\right)\end{array}$ & Level & $\begin{array}{c}\text { Thiamine / } \\
\left(\mathrm{mol} \mathrm{L}^{-1}\right)\end{array}$ & $\begin{array}{l}\mathrm{STGA}^{\mathrm{c}} / \\
\left(\mathrm{mol} \mathrm{L}^{-1}\right) \\
\end{array}$ & $\begin{array}{c}\text { PEG / } \\
(\mathrm{m} / \mathrm{v}) \%\end{array}$ & $\begin{array}{c}\mathrm{HCl} / \\
\left(\mathrm{mol} \mathrm{L}^{-1}\right) \\
\end{array}$ \\
\hline-1 & $5.0 \times 10^{-4}$ & $1.0 \times 10^{-3}$ & 0.01 & 0.01 & -1 & $2.5 \times 10^{-4}$ & $9.0 \times 10^{-4}$ & 0.01 & 0.10 \\
\hline 0 & $1.0 \times 10^{-3}$ & $2.0 \times 10^{-2}$ & 0.05 & 0.05 & 0 & $7.5 \times 10^{-4}$ & $1.6 \times 10^{-3}$ & 0.05 & 0.60 \\
\hline 1 & $1.5 \times 10^{-3}$ & $3.9 \times 10^{-2}$ & 0.09 & 0.09 & 1 & $1.3 \times 10^{-3}$ & $2.3 \times 10^{-3}$ & 0.09 & 1.10 \\
\hline
\end{tabular}

${ }^{\mathrm{a}} \mathrm{N}$-Acetylcysteine; ${ }^{\mathrm{b}}$ polyethylene glycol; ${ }^{\mathrm{c}}$ silicotungstic acid. 
study, only the nephelometric data were discussed, but the turbidimetric data also presented the same results with low values of RSD. At this stage of development of the device, preliminary tests are necessary only to check the stability of the PMTN electronic circuit and not the chemical system under study, which thus explains the use of the empty cuvette (without solution) in the optical path. The nephelometric signal was about $90 \mathrm{mV}$ mainly due to reflection of the radiation by the wall of the cuvette and subsequently detected at $90^{\circ}$. However, before each analysis this spurious signal is read by the PMTN and discounted automatically from the analytical signal of radiation scattering by a software written in C language as described by Cantrell and Ingle. ${ }^{16}$ This small disadvantage does not compromise in any manner the results obtained with the equipment. In some cases, experimental results of turbidity or nephelometry were suppressed since they showed similar results and interpretations, avoiding that data might be presented repeatedly.

Multivariate optimization applied for determination of $\mathrm{N}$-acetylcysteine and thiamine in pharmaceutical formulations

In order to find the best parameter for $\mathrm{N}$-acetylcysteine and thiamine determination, a $2^{4}$ factorial design employing the variables and ranges shown in Table 1 was elaborated for each analyte under study. Altogether 19 experiments were carried out for each analyte, 16 from factorial design and 3 from the replicates at the central point with $n=3$. Only turbidimetric data (arbitrary units, a.u.) were shown in Figure 4, since nephelometric analyses presented the same results as those obtained by the turbidimetry. In fact, the variables that provide an increase in particle concentration

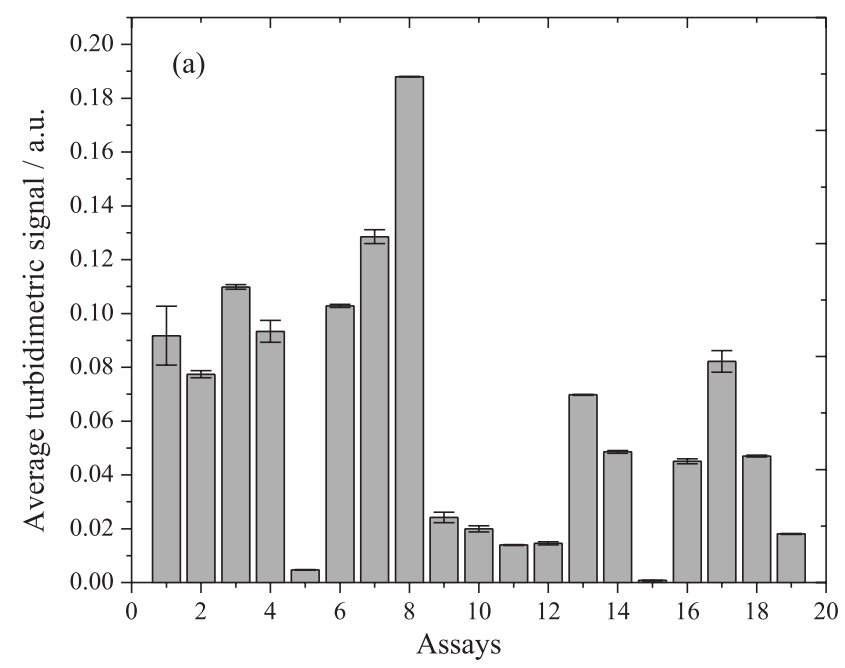

and also further stabilize it are the same for the turbidimetry or nephelometry.

As can be seen in Figure 4(a), assay 8 is the one which supplies the high analytical signal with good reproducibility and stability to determine $N$-acetylcysteine. Thus, reagent $(R)$, surfactant $(S)$, and $\mathrm{pH}$ should be set at their lower levels because a decrease of those variables causes an increase on the analytical signal. On the other hand, the analyte $(A)$ variable must be set at its higher level. The optimized concentration of analyte, reagent, surfactant, and solution $\mathrm{pH}$ to determine $\mathrm{N}$-acetylcysteine were $1.5 \times 10^{-3} \mathrm{~mol} \mathrm{~L}^{-1}, 1.0 \times 10^{-3} \mathrm{~mol} \mathrm{~L}^{-1}, 0.01 \%(\mathrm{~m} / \mathrm{v})$ and $0.01 \mathrm{~mol} \mathrm{~L}^{-1}(\mathrm{pH}=2)$, respectively.

After observing Figure 4(b), experiment 7 was selected for further experiments of thiamine determination. The increase of the reagent $(R)$ and analyte $(A)$ concentration leads to increases in the analytical signal for the studied levels. In contrast, lower levels of surfactant concentration and $\mathrm{pH}$ were preferable. Thus, the following parameters were selected on the method of thiamine: $(A)=1.3 \times 10^{-3} \mathrm{~mol} \mathrm{~L}^{-1}$, $(R)=2.3 \times 10^{-3} \mathrm{~mol} \mathrm{~L}^{-1},(S)=0.01 \%(\mathrm{~m} / \mathrm{v})$ and $\mathrm{pH}=1$. All further experiments were carried out with these optimized parameters to determine $N$-acetylcysteine and thiamine in pharmaceutical formulations applying the STN analyses.

Studies of potential interferences and recovery to determine $\mathrm{N}$-acetylcysteine and thiamine in pharmaceutical formulations

Potential interferences in the determination of $\mathrm{N}$-acetylcysteine with $\mathrm{Cu}^{2+}$ ions as reagent using the turbidimetric and nephelometric methods were investigated at concentrations of 100,10 , and 0.1 times the concentration of the standard solution of $5.0 \times 10^{-4} \mathrm{~mol} \mathrm{~L}^{-1}$

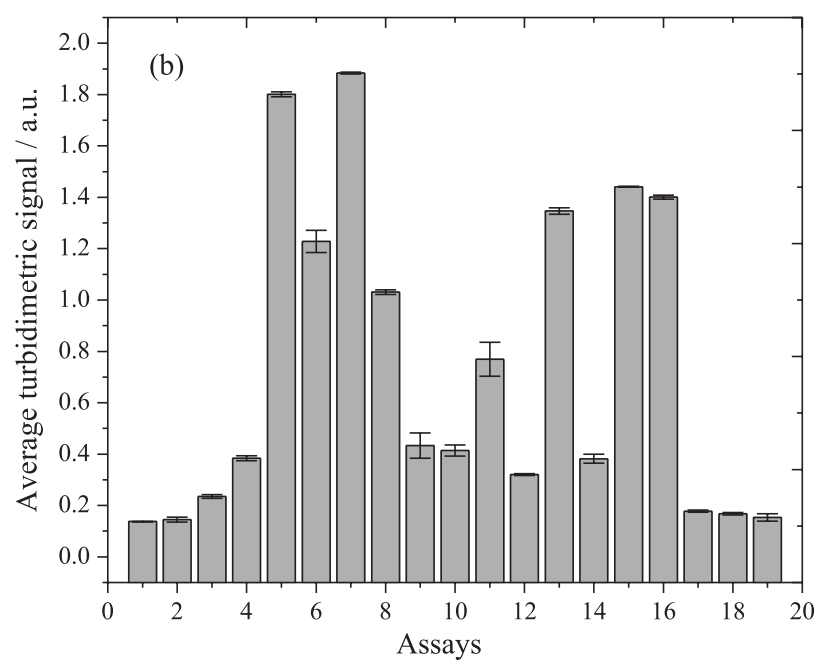

Figure 4. Results of the factorial design applied to determine $N$-acetylcysteine (a) and thiamine (b) in pharmaceutical formulations. Only turbidimetric data are shown $(465 \mathrm{~nm})$. 
of $\mathrm{N}$-acetylcysteine. For this purpose, the interference and recovery studies were evaluated and the turbidimetric results are discussed.

Among all contaminants present in the tablet and packaging of the pharmaceutical formulations which included saccharin, dipotassium hydrogen phosphate, crystalline cellulose, sucrose, sodium benzoate, EDTA, fructose and tartrazine, only $5.0 \times 10^{-2} \mathrm{~mol} \mathrm{~L}^{-1}$ sodium benzoate with an interference of $-28.5 \%$ and $5.0 \times 10^{-3} \mathrm{~mol} \mathrm{~L}^{-1}$ tartrazine with $264.0 \%$ of interference, respectively, cause the most perceived of interference. Sodium benzoate concentration $\left(5.0 \times 10^{-2} \mathrm{~mol} \mathrm{~L}^{-1}\right)$ caused a significant interference due to the complexation of $\mathrm{Cu}^{2+}$ by benzoate anions. By reducing the concentration of benzoate anions to $5.0 \times 10^{-4} \mathrm{~mol} \mathrm{~L}^{-1}$, this effect was significantly reduced to $-1.4 \%$.

Tartrazine presents a spectra of absorption in which wavelengths of the maxima absorption are within $400-470 \mathrm{~nm}$ (blue radiation), exactly in the same region of maximum emission of the blue LED $(465 \mathrm{~nm})^{41}$ leading to a decrease in the intensity of transmitted light and consequently inducing the positive errors which were found. Therefore, the determination of $\mathrm{N}$-acetylcysteine in the presence of these substances was carried out in the infrared spectral region $\left(\lambda_{\text {max }}=880 \mathrm{~nm}\right)$. In fact, when the IR LED was used, the interference becomes negligible (1.6\%).

Recovery studies were performed using three different samples of $\mathrm{N}$-acetylcysteine (two tablet samples and one sachet of $\mathrm{N}$-acetylcysteine containing tartrazine) by adding three different aliquots of $N$-acetylcysteine standard solutions $(n=3)$. The turbidimetric data at 465 and $880 \mathrm{~nm}$ are discussed. The values of recovery varied in the range of 94.9 to $104.5 \%$, indicating the absence of matrix effect. Besides, there is no significant difference between the results obtained in the recovery tests for colorless samples measured at $465 \mathrm{~nm}$ and colored samples ( $N$-acetylcysteine containing tartrazine) measured at $880 \mathrm{~nm}$.

The same procedure was performed to test the potential interference in the method for the determination of thiamine in pharmaceutical formulations. This time, the nephelometric results carried out at 465 and $880 \mathrm{~nm}$ are discussed in order to evaluate the versatility of the developed instrument. The contaminants were added at concentrations of 100,1 and 0.1 times to the analyte concentration $\left(6.0 \times 10^{-5} \mathrm{~mol} \mathrm{~L}^{-1}\right.$ thiamine $)$.

The following contaminants were then analyzed: povidone, ascorbic acid, starch, lactose, ferrous sulfate, zinc sulfate, riboflavin and cyanocobalamin. Interferences studies with all combined concomitants were also realized. The $6.0 \times 10^{-3} \mathrm{~mol} \mathrm{~L}^{-1}$ povidone solution showed a significant interference of $16.4 \%$. Povidone is a stabilizer and together with PEG acts as a powerful surfactant changing the features of the formed suspension. Thus, greater povidone concentration induces increased turbidity of the solution generating a considerable positive error. However, at lower povidone concentration studied $\left(6.0 \times 10^{-5} \mathrm{~mol} \mathrm{~L}^{-1}\right)$, the interference is negligible, ca. $0.7 \%$. Among the other contaminants, only riboflavin (vitamin B2, yellow coloration) and cyanocobalamin (vitamin B12, red coloration) showed considerable interference with values of -80.0 and $-10.2 \%$, respectively. In fact, this absorption phenomena lead to a decrease of scattered light that reaches the detector at an angle of $90^{\circ}$, and consequently, negative errors were obtained by the nephelometric analyses; this effect is opposite to that of turbidimetry as observed previously. To overcome this drawback, measurements at a wavelength of $880 \mathrm{~nm}$ (IR) were performed and the results showed that there is no significant interference $(<1.0 \%)$. Thus, thiamine can be determined easily in matrices containing these substances.

Recovery tests were carried out using three different pharmaceutical samples and recoveries between 97.4 and $102.5 \%$ were obtained. These values suggest that contaminants in the sample matrix had little influence in the analysis.

Therefore, the nephelometric and turbidimetric determinations of $N$-acetylcysteine and thiamine were performed at $465 \mathrm{~nm}$ for further experiments because measurements in this wavelength are more sensitive than at $880 \mathrm{~nm}$, since the lower wavelength suffers greater radiation scattering. ${ }^{3,17}$ On the other hand, the measurements at 880 $\mathrm{nm}$ were always employed to avoid the interference effect of colored sample solutions. ${ }^{12,17}$ Thus, the figures of merit were obtained employing the measurements at $465 \mathrm{~nm}$ for both techniques.

Analytical performance obtained by the application of the STN to determine N-acetylcysteine and thiamine. A comparison between the applied methods

All figures of merit obtained by application of the STN method with PMTN to determine $N$-acetylcysteine and thiamine were summarized in Tables 2 and 3 in order to compare the performance of the turbidimetric and nephelometric methods applied. The analytical curves are shown as Supplementary Information, Figure S2.

The use of the PMTN to determine $N$-acetylcysteine by STN method employing copper ions as a precipitant reagent showed satisfactory analytical sensitivity. By applying the nephelometric method, it is possible to obtain a lower limit of detection and a wider linear range as compared with the turbidimetric method. These 
Table 2. Figures of merit of linear regression obtained by application of the proposed equipment employing the method based on the reaction between $\mathrm{N}$-acetylcysteine and $\mathrm{Cu}^{2+}$ as a reagent of precipitation with measurement at $465 \mathrm{~nm}$

\begin{tabular}{lcc}
\hline Parameters & Turbidimetric results & Nephelometric results \\
\hline Equation of regression & T. S. ${ }^{\text {a }}($ a.u. $)=(-7.29 \pm 0.02) \times 10^{-4}+(75.10 \pm 0.02) \times[\mathrm{N}-\text { act. }]^{\text {c }}$ & N. S. $(\mathrm{mV})=(-2 \pm 1)+(7.4 \pm 0.3) \times 10^{4}[\mathrm{~N}-\mathrm{act}]$. \\
Linear range & $5.0 \times 10^{-5}-1.2 \times 10^{-3}\left(\mathrm{~mol} \mathrm{~L}^{-1}\right)$ & $8.0 \times 10^{-5}-5.0 \times 10^{-3}\left(\mathrm{~mol} \mathrm{~L}^{-1}\right)$ \\
Coefficient of correlation (r) & 0.996 & 0.998 \\
$\mathrm{LOD}^{\mathrm{d}}$ & $7.5 \times 10^{-6} \mathrm{~mol} \mathrm{~L}^{-1}$ & $2.6 \times 10^{-6} \mathrm{~mol} \mathrm{~L}^{-1}$ \\
$\mathrm{LOQ}^{\mathrm{e}}$ & $2.5 \times 10^{-5} \mathrm{~mol} \mathrm{~L}^{-1}$ & $8.7 \times 10^{-6} \mathrm{~mol} \mathrm{~L}^{-1}$ \\
Repeatability, RSD $(n=3)$ & $2.5 \%$ for $3.0 \times 10^{-4} \mathrm{~mol} \mathrm{~L}^{-1}$ & $1.4 \%$ for $3.0 \times 10^{-4} \mathrm{~mol} \mathrm{~L}^{-1}$ \\
\hline
\end{tabular}

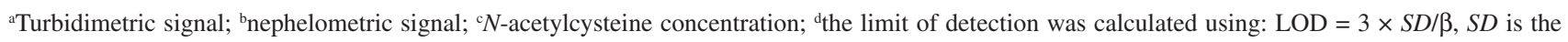

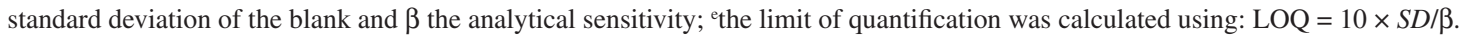

Table 3. Figures of merit of linear regression obtained by application of the precipitation reaction between thiamine and silicotungstic acid employing the PMNT with measurement at $465 \mathrm{~nm}$

\begin{tabular}{lcc}
\hline Parameters & Turbidimetric results & Nephelometric results \\
\hline Equation of regression & T. S. ${ }^{a}$ (a.u. $)=(0.05 \pm 0.02)+(8.3 \pm 0.2) \times 10^{3}$ [thiamine] & N. S. ${ }^{\mathrm{b}}(\mathrm{mV})=(7 \pm 1)+(2.4 \pm 0.1) \times 10^{6}[$ thiamine] \\
Linear range & $5.0 \times 10^{-6}-1.0 \times 10^{-4}\left(\mathrm{~mol} \mathrm{~L}^{-1}\right)$ & $5.0 \times 10^{-6}-2.5 \times 10^{-4}\left(\mathrm{~mol} \mathrm{~L} \mathrm{~L}^{-1}\right)$ \\
Coefficient of correlation (r) & 0.996 & 0.998 \\
LOD & $3.11 \times 10^{-8} \mathrm{~mol} \mathrm{~L}^{-1}$ & $5.91 \times 10^{-8} \mathrm{~mol} \mathrm{~L}^{-1}$ \\
LOQ & $1.03 \times 10^{-7} \mathrm{~mol} \mathrm{~L}^{-1}$ & $1.97 \times 10^{-7} \mathrm{~mol} \mathrm{~L}^{-1}$ \\
Repeatability, RSD $(n=3)$ & $0.64 \%$ to $5.0 \times 10^{-5} \mathrm{~mol} \mathrm{~L}^{-1}$ & $0.60 \%$ to $5.0 \times 10^{-5} \mathrm{~mol} \mathrm{~L}^{-1}$ \\
\hline
\end{tabular}

${ }^{a}$ Turbidimetric signal; bnephelometric signal.

limits of detection were lower than some reported in the literature. ${ }^{37,42}$ In fact, with this equipment, it was possible to acquire low limits of detections of $2.6 \times 10^{-6}$ and $7.5 \times 10^{-6} \mathrm{~mol} \mathrm{~L}^{-1}$ for nephelometric and turbidimetric analyses, respectively. The methods show good RSD values as can be seen in Table 2 .

The results regarding the determination of thiamine by employing STN methods with PMTN showed to be very encouraging due to the low limits of detections acquired for both methods, wide linearity and high analytical sensitivity (slope of analytical curve) are also obtained. The good performance of the PMTN demonstrates its usefulness, since these results are similar to those reported in the literature. ${ }^{43,44}$ Moreover, the detection limits obtained when applying the nephelometric method were higher than those obtained when employing the turbidimetric method. Thus, this result was opposite to the one found previously in the determination of $\mathrm{N}$-acetylcysteine, where the nephelometric method shows lower limit of detections than those provided by the turbidimetric method, although the same conditions (temperature, stirring, and time of stabilization) were employed for each technique. Thus, we believe that the particle size parameter may be the factor which most influences this behavior as reported in the literature. ${ }^{1,3,4,6}$ At the beginning, it was noted that the reaction between $\mathrm{N}$-acetylcysteine and copper ions formed a suspension in which particle sizes were greater than those produced by the reaction between thiamine and silicotungstic acid, because these particles can be seen by naked eye. Thus, a study of particle size was performed employing the DLS technique.

\section{Light scattering and particles size}

According to the results obtained from the STN studies ${ }^{45,46}$ for the precipitate formed in the of $\mathrm{N}$-acetylcysteine method with $\mathrm{Cu}^{2+}$ ions, it can be verified that the suspension contains large particles or aggregates that presented a particle size larger than the upper limit (13751.5 nm) given by the equipment. In other words, it is outside the technical specifications of the equipment applied to DLS measurements. On the other hand, the particle size of the precipitate formed by the reaction between thiamine and silicotungstic acid produced particles whose sizes were much smaller than those obtained by the $N$-acetylcysteine method. The graph of particles size distribution $v s$. intensity is shown in Figure 5.

As can be seen in the graph, there are two peaks of maximum intensity, one in $1376 \mathrm{~nm}$ ( $97.6 \%$ of the relative signal intensity) and another in $5560 \mathrm{~nm}$ (2.4\% of the relative signal intensity). Thus, it can be deduced that the peak in $1376 \mathrm{~nm}$ refers to an average diameter of the 


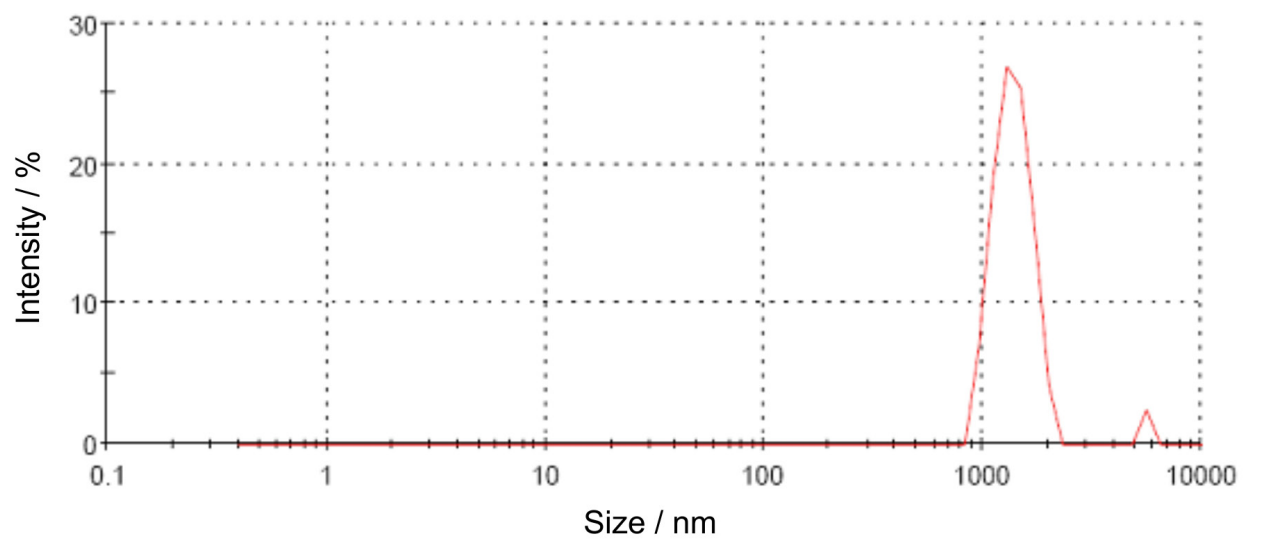

Record: thiamine

Figure 5. Study of particle size for the precipitate formed in the reaction between thiamine and silicotungstic acid. Graphic obtained employing a Zetasizer from Malvern Instruments model Nano ZS using a LASER of He-Ne with maximum emission at $632.8 \mathrm{~nm}$.

particles in suspension and $5560 \mathrm{~nm}$ refers to aggregation processes between the particles. According to these results, we can conclude that, in this case, larger particles (precipitate formed by reaction between $N$-acetylcysteine and $\mathrm{Cu}^{2+}$ ions) allow the nephelometric technique to achieve lower limits of detection than those obtained when applying the turbidimetric method. On the other hand, small particles are favorable for turbidimetric analyses (precipitate formed by the reaction between thiamine and silicotungstate ions). In fact, small particles lead to the accentuated increase of radiation scattering intensity in all directions, increasing the turbidimetric signal by decreasing the amount of radiation reaching the detector (decreasing the signal of transmittance). ${ }^{1,3,4,40}$ This attenuation of radiation was more pronounced than the effect of radiation scattering at $90^{\circ}$ and thus the turbidimetric method presented a lower limit of detection than that obtained by the nephelometric technique. On the other hand, large particles cause an opposite effect because these particles do not scatter the radiation with the same efficiency of the small particles, mostly angles greater than $90^{\circ}$. This effect leads to a less accentuated decrease of the transmitted radiation intensity, consequently reducing the turbidimetric signal more strongly than the nephelometric signal.

This is reinforced analyzing the analytical sensitivity and the limit of detection obtained using both turbidimetric and nephelometric methods for thiamine (small particles) and $\mathrm{N}$-acetylcysteine determination (large particles). The methods for thiamine detection showed an analytical sensitivity 100 times higher mainly due to the smaller particles, and consequently, the limit of detection was 100 times lower than the methods for $N$-acetylcysteine detection.

Thus, the PMTN based on radiation scattering can distinguish the scattering patterns of large particles from small particles because large particles principally scatter radiation to small angles away from the incident radiation beam, while small particles cause more effective scattering for all directions.

Analysis of $\mathrm{N}$-acetylcysteine and thiamine concentrations in pharmaceutical formulations employing conductometry and voltammetry, respectively, used as comparative techniques

The method developed by Janegitz et al. ${ }^{37}$ was used as a comparative method. This method is based on the conductometric titration of $\mathrm{N}$-acetylcysteine with $\mathrm{Cu}^{2+}$ ions. In Table 4, the results regarding concentration of $\mathrm{N}$-acetylcysteine in pharmaceutical formulations when employing the STN method and the conductometric method used as a reference are shown.

As can be observed by applying the $F$-test for each analyzed sample, the values obtained were lower than 10.0, well below the critical value (19.0) for a 95\% confidence level. Similarly, the values obtained by applying $t$-paired tests were also below the critical value (4.30). From these results, it can be concluded that there are no statistical differences between the results at a confidence level of $95 \%$. Thus, the PMTN can be used to determine $N$-acetylcysteine by applying the STN method with good results even in the presence of colored substances.

To determine thiamine in pharmaceutical formulations, the method developed by Lingane and Davies ${ }^{28}$ based on the differential pulse polarographic technique was applied. In Table 5, the results of the thiamine concentration in pharmaceutical formulations employed for STN method are shown, as well as the polarographic method which was used as a reference. 
Table 4. Results obtained by the application of the conductimetric method and the PMTN for two samples of $N$-acetylcysteine analyzed in triplicate $(n=3)$

\begin{tabular}{lcccccccc}
\hline $\mathrm{S}^{\mathrm{a}}$ & $\mathrm{R}^{\mathrm{b}} / \mathrm{mg}$ & $\mathrm{T}^{\mathrm{c}}(1) / \mathrm{mg}$ & $\mathrm{N}^{\mathrm{d}}(2) / \mathrm{mg}$ & $\mathrm{E}_{1}^{\mathrm{e}} / \%$ & $\mathrm{E}_{2}^{\mathrm{e}} / \%$ & $F_{1}-\mathrm{Test}^{\mathrm{f}}$ & $F_{2}-\mathrm{Test}^{\mathrm{f}}$ & $t_{1}-\mathrm{Test}^{\mathrm{f}}$ \\
\hline $\mathrm{A}$ & $193 \pm 2$ & $190.3 \pm 0.8$ & $191.4 \pm 0.9$ & -1.4 & -0.8 & 8.9 & 4.5 \\
$\mathrm{~B}^{\mathrm{g}}$ & $570 \pm 2$ & $575.9 \pm 0.7$ & $572.5 \pm 0.9$ & 1.0 & 0.4 & 4.0 & 0.8 \\
\hline
\end{tabular}

$F$-test $(2,2, \alpha=0.05)=19.0$ and $t$-test $(2,2, \alpha=0.05)=4.3$ (paired), with $n=3$; ${ }^{\text {asample; }}{ }^{\mathrm{b}}$ reference; 'turbidimetry; ${ }^{\mathrm{d}}$ nephelometry; ${ }^{\mathrm{e}} \mathrm{E}_{1}$ is the relative error obtained by comparison between the turbidimetric (1) and the comparative method and $\mathrm{E}_{2}$ is the relative error between the nephelometric (2) and comparative method; ${ }^{\mathrm{f}} F_{1}$ test, $F_{2}$ test, $t_{1}$ test, and $t_{2}$ test are the results of application of $F$-test and $t$-paired test under results supplied by the turbidimetric (1) and nephelometric (2) methods in comparison to the comparative method, respectively; ${ }^{g} \mathrm{~B}$ is the sample containing tartrazine (dye) analyzed with IR LED at $880 \mathrm{~nm}$.

Table 5. Thiamine in pharmaceutical samples analyzed by the methods of differential pulse voltammetry (comparative) and the sequential turbidimetric and nephelometric (STN) method with the PMTN (465 nm)

\begin{tabular}{lccccccc}
\hline $\mathrm{S}^{\mathrm{a}}$ & $\mathrm{R}^{\mathrm{b}} / \mathrm{mg}$ & $\mathrm{T}^{\mathrm{c}}(1) / \mathrm{mg}$ & $\mathrm{N}^{\mathrm{d}}(2) / \mathrm{mg}$ & $\mathrm{E}_{1}^{\mathrm{e}} / \%$ & $\mathrm{E}_{2}^{\mathrm{e}} / \%$ & $F_{1}-\mathrm{Test}^{\mathrm{f}}$ & $F_{2}-\mathrm{Test}^{\mathrm{f}}$ \\
\hline $\mathrm{A}$ & $307.3 \pm 0.9$ & $304.5 \pm 0.1$ & $303.0 \pm 0.1$ & -0.9 & -1.4 & 3.0 & 1.4 \\
$\mathrm{~B}$ & $288.9 \pm 0.3$ & $294.3 \pm 0.2$ & $284.3 \pm 0.3$ & 1.9 & -1.6 & 1.5 & 1.7 \\
$\mathrm{C}$ & $292.1 \pm 0.9$ & $299.9 \pm 0.8$ & $299.0 \pm 0.9$ & 2.7 & 2.4 & 1.0 & 1.0 \\
\hline
\end{tabular}

$F$-test $(2,2, \alpha=0.05)=19.0$ and $t$-test $(2,2, \alpha=0.05)=4.3$ (paired), with $n=3$; ${ }^{\text {asample; }}{ }^{\mathrm{b}}$ reference; ${ }^{\text {cturbidimetry; }}{ }^{\mathrm{d}}$ nephelometry; ${ }^{\mathrm{e}} \mathrm{E}_{1}$ is the relative error obtained by comparison between the turbidimetric (1) and the comparative method; and $\mathrm{E}_{2}$ is the relative error between the nephelometric (2) and differential pulse voltammetry used as comparative method; ${ }^{\mathrm{f}} F_{1}$ test, $F_{2}$ test, $t_{1}$ test, and $t_{2}$ test are the results of application of $F$-test and $t$-paired test under results supplied by the turbidimetric (1) and nephelometric (2) methods in comparison to the differential pulse voltammetry method, respectively.

Analyzing the values obtained by the application of $F$-test and $t$-paired test, all values are below the critical (tabulated) values, and therefore there are no differences between the applied methods for a $95 \%$ level of confidence. The largest relative error was only $2.7 \%$. According to the results, the PMTN can be used in both methods for the determination of $N$-acetylcysteine and thiamine with similar results to those achieved employing the comparative methods because there are no significant differences between them at the confidence interval of $95 \%$.

Additionally, the proposed method is also attractive in the environmental point of view mainly because in situ and online analyses can be easily performed since it has a fast response, good portability, low power consumption, and practicality, since acquired experimental data can be filed in the memory of the microcontroller (or external memory). Therefore, once properly calibrated, the equipment is able to identify the concentration of the analytes without requiring recalibration since the concentration values are not more than $10 \%$ different from values of the standard solutions. In the case of greater divergence, a message will be displayed on the LCD screen alerting the need of new calibration of the PMTN.

\section{Conclusions}

The possibility of analyzing by the turbidimetric and nephelometric methods at practically the same time ( $0.25 \mathrm{~s}$ between each analysis) was important to study the characteristics of each technique applied to two different cases studies ( $N$-acetylcysteine and thiamine). With two applications, it is possible to compare the linearity, analytical sensitivity, LOD, LOQ and repeatability furnished by these different procedures. In addition, it was concluded that the performance of the employed analytical methods is not only a function of the power of incident radiation and sensitivity of the sensor but also a function of the particle size. In fact, the nephelometric method presented a lower limit of detection than that of the turbidimetric method in the case of $\mathrm{N}$-acetylcysteine determination in which the particles formed were larger. On the other hand, the turbidimetric method for thiamine determination presented better results by producing smaller size particles. The same conditions were used in both turbidimetric and nephelometric methods and particle size was the decisive variable for the obtained results. Thus, the PMTN showed a quite versatile detection system that allow even more capabilities than those supplied by a conventional turbidimeter or nephelometer since configurations for multi-beam and multi-detector arrangements were easily implemented.

\section{Supplementary Information}

Supplementary information of the stability of PMTN and analytical curves (Figure S1 and S2, respectively) are available free of charge at http://jbcs.org.br as a PDF file.

\section{Acknowledgments}

The authors are grateful to the Conselho Nacional de Desenvolvimento Científico e Tecnológico (CNPq), Fundação de Apoio a Pesquisa do Estado de São Paulo 
(FAPESP) and Coordenação de Aperfeiçoamento de Pessoal de Nível Superior (CAPES) for their financial support and scholarships.

\section{References}

1. Braun, R. D.; Radiative Scattering: Introduction to Instrumental Analysis; McGraw-Hill: New York, 1987.

2. Skoog, D. A.; Leary, J. J.; Principles of Instrumental Analysis, $4^{\text {th }}$ ed.; Saunders College Publishing: New York, 1992.

3. Ingle Jr., J. D; Crouch, S. R.; Spectrochemical Analysis, $1^{\text {st }}$ ed.; Prentice-Hall Inc.: New Jersey, 1988.

4. Kleizen, H. H.; Putter, A. B.; Van der Beek, M.; Huynink, S. J.; Filtr. Sep. 1995, 32, 897.

5. Liu, H. H.; Dasgupta, P. K.; Anal. Chim. Acta 1996, 326, 13.

6. Morais, I. P.; Toth, I. V.; Rangel, A. O; Spectroc. Lett. 2006, 39 , 547.

7. Dasgupta, P. K.; Eom, I.; Morris, K. J.; Li, J.; Anal. Chim. Acta 2003, 500, 337.

8. Somnam, S.; Grudpan, K.; Jakmunee, J.; Maejo Int. J. Sci. Technol. 2008, 2, 172.

9. Palma, A. J.; Ortigosa, J. M.; Lapresta-Fernández, A.; Fernández-Ramos, M. D.; Carvajal, M. A.; Capitán-Vallvey, L. F.; Rev. Sci. Instrum. 2008, 79, 103105.

10. Gaião, E. D.; Santos, S. R. B.; Santos, V. B.; Nascimento, E. C. L.; Lima, R. S.; Araujo, M. C. U.; Talanta 2008, 75, 792.

11. Suarez, W. T.; Pessoa-Neto, O. D.; Santos, V. B.; Nogueira, A. R. A.; Faria, R. C.; Fatibello-Filho, O.; Puyol, M.; Chamarro, J. A.; Anal. Bioanal. Chem. 2010, 398, 1525.

12. Ródenas-Torralba, E.; Morales-Rubio, A.; Lavorante, A. F.; Reis, B. F.; de la Guardia, M.; Talanta 2007, 73, 742.

13. Garcia, A.; Perez, M. A.; Ortega, G. J. G.; Dizy, J. T.; IEEE Trans. Instrum. Meas. 2007, 56, 907.

14. Postolache, O. A.; Girao, P. M. B. S.; Perreira, J. M. D.; Ramos, H. M. G.; IEEE Sens. J. 2007, 7, 677

15. Omar, A. F. B.; MatJafri, M. Z. B.; Sensors 2009, 9, 8311.

16. Cantrell, K. M.; Ingle, J. D.; Anal. Chem. 2003, 75, 27.

17. Santos, V. B.; Guerreiro, T. B.; Suarez, W. T.; Faria, R. C.; Fatibello-Filho, O.; J. Braz. Chem. Soc. 2011, 22, 726.

18. Kabasakal, L.; Sehirli, A. O.; Cetinel, S.; Cikler, E.; Gedik, N.; Sener, G.; Life Sci. 2004, 75, 2329.

19. Ogwu, V.; Cohen, G.; Free Radical Biol. Med. 1998, 25, 362.

20. Huang, X. J.; Kok, W. T.; J. Liq. Chromatogr. 1991, 14, 2207.

21. Oe, T.; Ohyagi, T.; Naganuma, A.; J. Chromatogr., B: Anal. Technol. Biomed. Life Sci. 1998, 708, 285.

22. Toussaint, B.; Ceccato, A.; Hubert, P.; Graeve, J.; Pauw, E.; Crommen, J.; J. Chromatogr., A 1998, 819, 161.

23. Toussaint, B.; Pitti, C.; Streel, B.; Ceccato, A.; Hubert, P.; Crommen, J.; J. Chromatogr., A 2000, 896, 191.
24. Koike, H.; Iijima, M.; Mori, K.; Hattori, N.; Ito, H.; Hirayama, M.; Sobue, G.; Nutrition 2004, 20, 961.

25. Aboul-Kasim, E.; J. Pharm. Biomed. Anal. 2000, 22, 1047.

26. Association of Official Analytical Chemists; Official Methods of Analysis of AOAC; AOAC International: Arlington, 1984.

27. British Pharmacopoeia; Her Majesty's Stationery Office: London, 1958.

28. Lingane, J. J.; Davies, O. L.; J. Biol. Chem. 1941, 137, 567.

29. Campiglio, A.; Analyst 1994, 119, 2209.

30. Vidovic, S.; Stojanovic, B.; Veljkovic, J.; Prazic-Arsic, L.; Roglic, G.; Manojlovic, D.; J. Chromatogr., A 2008, 1202, 155.

31. Okamoto, H.; Nakajima, T.; Ito, Y.; J. Chromatogr., A 2003, 986, 153.

32. Lopez-Flores, J.; Cordova, M. L. F. D.; Molina-Diaz, A.; Anal. Chim. Acta 2005, 535, 161.

33. Rocha, F. R. P.; Fatibello-Filho, O.; Reis, B. F.; Talanta 2003, $59,191$.

34. http://www.alldatasheet.com/datasheet-pdf/pdf/203057/TAOS/ TSLB257.html accessed in January 2011.

35. http://pdf1.alldatasheet.com/datasheet-pdf/view/203027/TAOS/ TSL260R-LF.html accessed in January 2011.

36. http://ww1.microchip.com/downloads/en/DeviceDoc/39632e. pdf accessed in January 2011.

37. Janegitz, B. C.; Suarez, W. T.; Fatibello-Filho, O.; Marcolino-Jr., L. H.; Anal. Lett. 2008, 41, 3264.

38. Costa-Neto, C. O.; Pereira, A.; Aniceto, C.; Fatibello-Filho, O.; Talanta 1999, 48, 659.

39. Jiang, X. Y.; Chen, X. Q.; Xu, M.; J. Food Drug Anal. 2007, $15,178$.

40. Shaw, D. J.; Introduction to Colloid and Surface Chemistry, $4^{\text {th }}$ ed.; Butterworth-Heinemann: Oxford, 1992.

41. Bagirova, V. L.; Mit'kina, L. I.; Pharm. Chem. J. 2003, 37, 558.

42. Suarez, W. T.; Vieira, H. J.; Fatibello-Filho, O.; J. Braz. Chem. Soc. 2007, 18, 1028.

43. Xing, J.; Wang, F.; Zou, J.; Chen, X.; J. Nanosci. Nanotechnol. 2010, 10, 5783.

44. Li, Y.; Wang, P.; Wang, X.; Cao, M.; Xia, Y.; Cao, C.; Liu, M.; Zhu, C.; Microchim. Acta 2010, 169, 65.

45. Kaszuba, M.; Corbett, J.; Watson, F. M.; Jones, A.; Phil. Trans. R. Soc. A 2010, 368, 4439.

46. Berne, B. J.; Pecora, R.; Dynamic Light Scattering: with Applications to Chemistry, Biology and Physics; Dover Publications: New York, 2000.

Submitted: February 14, 2011

Published online: August 18, 2011

FAPESP has sponsored the publication of this article. 


\section{Evaluation of Turbidimetric and Nephelometric Techniques for Analytical Determination of $\mathrm{N}$-Acetylcysteine and Thiamine in Pharmaceutical Formulations Employing a Lab-Made Portable Microcontrolled Turbidimeter and Nephelometer
Vagner B. dos Santos, ${ }^{a}$ Thiago B. Guerreiro, ${ }^{a}$ Willian T. Suarez, ${ }^{b}$ Ronaldo C. Faria ${ }^{a}$ and Orlando Fatibello-Filho*, \\ ${ }^{a}$ Departamento de Química, Universidade Federal de São Carlos, Centro de Ciências Exatas e de Tecnologia, CP 676, 13560-970 São Carlos-SP, Brazil \\ ${ }^{\mathrm{b}}$ Departamento de Química, Universidade Federal de Viçosa, Centro de Ciências Exatas e Tecnológicas, 36570-000 Viçosa-MG, Brazil}

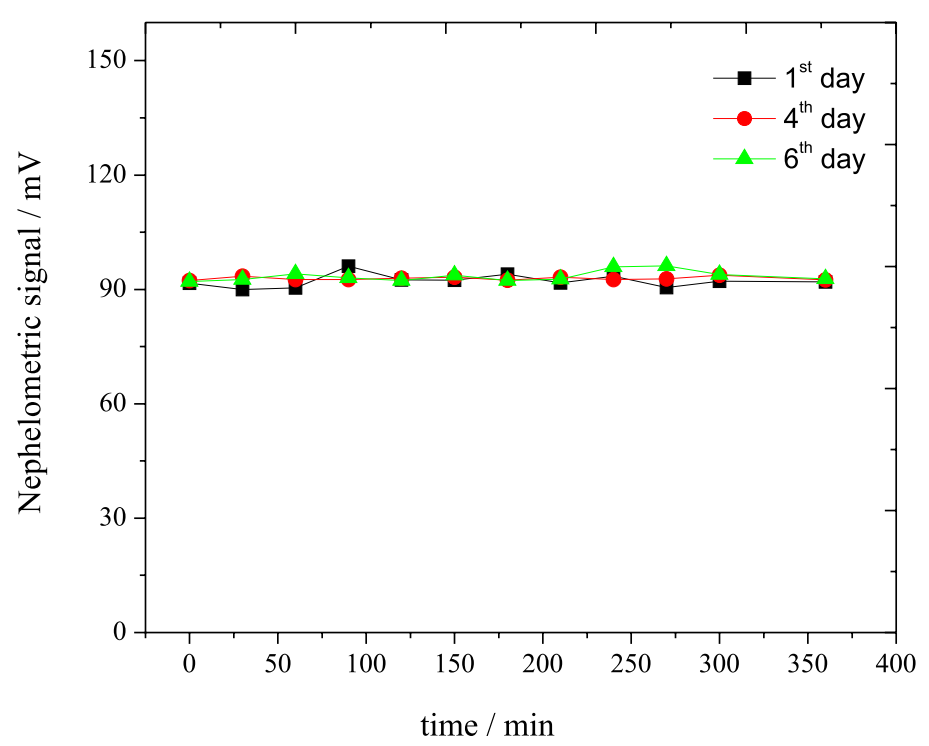

Figure S1. Evaluation of the stability of PMTN. Monitoring performed for a period of $6 \mathrm{~h}$ on three different days. Only nephelometric data in mV are shown $(465 \mathrm{~nm})$. 

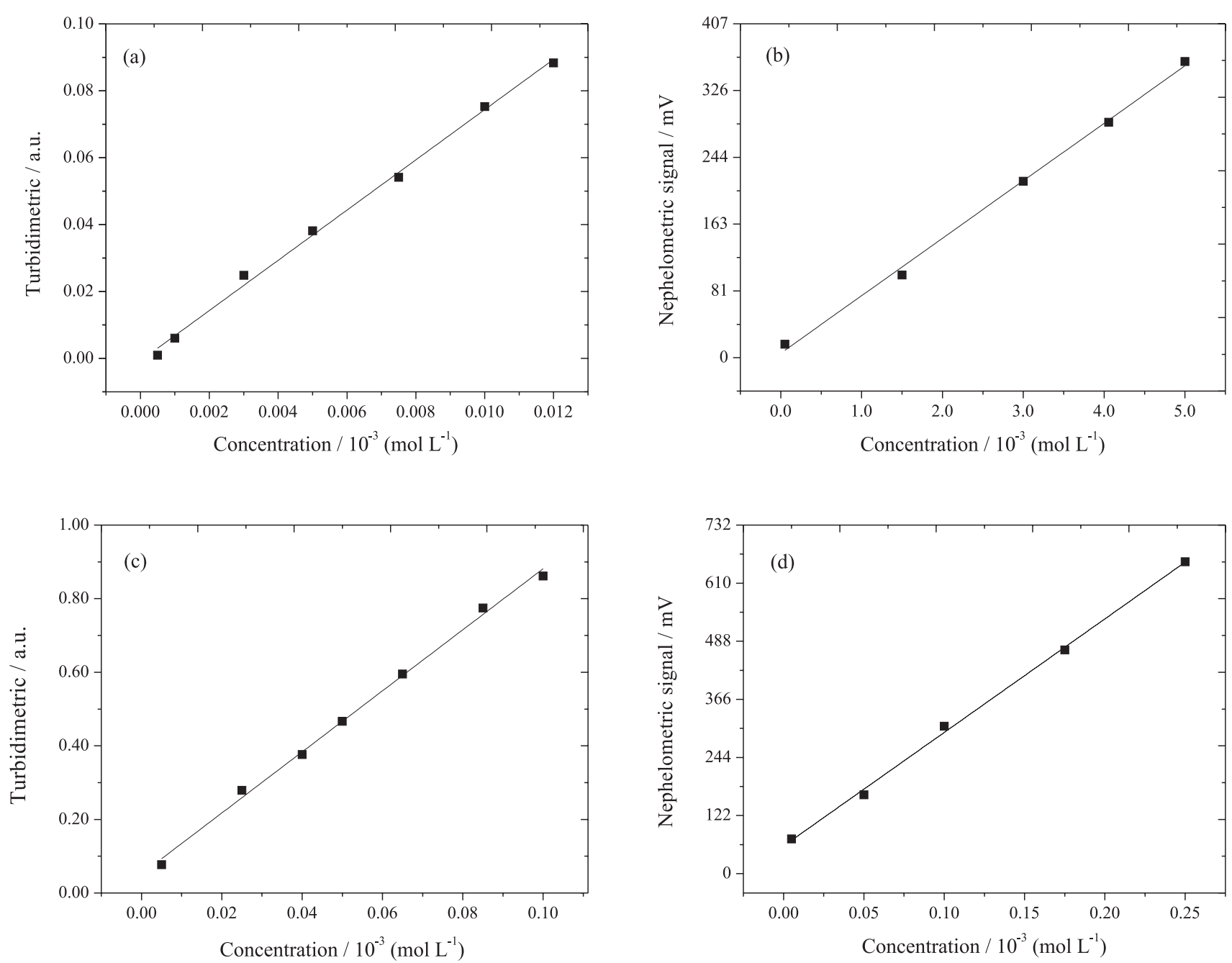

Figure S2. Analytical curves for $N$-acetylcysteine in the (a) turbidimetric and (b) nephelometric analyses. Analytical curves for thiamine with (c) turbidimetric and (d) nephelometric detections. All the measurements were performed at $465 \mathrm{~nm}$. 